\title{
The Empirical Analysis of Interview Ability of University Students
}

\author{
Ma Wei \\ XI'AN JIAOTONG UNIVERSITY \\ Xi'an, China \\ LiuYang \\ XI'AN JIAOTONG UNIVERSITY \\ Xi'an, China
}

\author{
Luo Xian \\ XI'AN JIAOTONG UNIVERSITY \\ Xi'an, China \\ Wei Jin \\ XI'AN JIAOTONG UNIVERSITY \\ $\mathrm{Xi}$ 'an, China
}

\begin{abstract}
As for one of the main way to test the comprehensive ability of college graduates, interview is the key link when measuring all-round capabilities. This paper adopts empirical research method to explore the absence of the graduates' interview ability and the effects of the backward idea to interview ability. The results indicate that there is great difference about the cognition of the decisive factor to interview result between the graduates and the employers. It is proved that this big difference between the graduates and the employers also exists in the cognition of the constitution of interview ability and the evaluation to the lever of the graduates' interview ability.
\end{abstract}

Keywords-Interview ability; University graduates; Cognitive differences; comprehensive ability

\section{INTRODUCTION}

The employment of college graduates is one of the major issues to be solved in our country. In 1999, our country began to implement the policy of large-scale enrollment expansion of colleges and universities, which directly led to the rapid expansion of the scale of graduates. From 2004 to 2010, the number of college graduates from 2800000 to 6310000 , an increase of 1.25 times in 7 years. While in recent years, the employment rate rose slightly, in 2010 it reached a high of $89.6 \%$, but in previous years the unemployment of college students is accumulated, forming a huge highly educated unemployed population, caused the long-run total amount of employment of college graduates becoming a difficult problem in our country. However, the embarrassing phenomenon is found that "it's difficult to be employed for graduates", but "it's hard to hair good stuff for enterprise" at the same time. Many scholars in the study of university graduates' difficult in getting job have proposed the university graduates have the "idea lag", "the comprehensive quality is not good" and "the practical ability is poor" and so on. However, at the same background, why an A was admitted, but a B failed off? The author believes that the basic knowledge is important, but the interview ability is the most important factor for college students to apply for a job (and even in the future career and promotion). Therefore, it has an important significance to study the actual level of college students' interview ability and their cognitive of the interview ability, to clarify the college graduates' cognitive errors, to help college students have the ability to improve the personal interview ability, improve the guidance of employment work, and generally improve the graduates' employment competitiveness and job satisfaction.

Interview is the most ancient, and also the most vitality of a talent quality evaluation method [1]. The interview content summarized by some scholars into three attributes: (1) two-way selection; (2) comprehensive quality; (3)take the seat according to the number[2]. At present, there is no unified definition of "interview ability", and even few scholars have studied the problem of "interview ability". The related research mainly concentrates in aspect about the interview examination content and the interview technique. In detail, the researches including interview etiquette [3], language competence [4], the content of the speech, the fluency and calm of speech [5] and more. There are a number of scholars to conclude the content of the interview, finding that seven core qualities like aggressive and passion, communication skills, successful experience, rational thinking, workplace performance, planning and organization skills and the ability to stress are the most impressed abilities to the interviewer [6].After doing a summary of common interview questions. Guo Xue Song found that from the point of ability, the investigation is mainly about the job seekers' basic quality, its contents generally include: analytic ability; communication ability; (3) planning ability; (4) innovation ability;(5)learning ability;(6) adaptive ability; (7)the leadership ability;(8) the stress management skills;(9)teamwork ability; (10)self-management ability [7].According to the survey about the effective exchange and invalid exchange of the interview, Lois Einhorn found that successful candidates showed more can be identified by the interviewer behavior, such as supporting arguments, thinking closely, clear ideas and bringing effective communication [8].

Throughout the existing research, scholars have explored the basic quality of candidates in the interview, to help college graduates to prepare for the interview in advance. But it has not yet been specifically defined and studied the ability of the interview. In addition, almost all of the studies are from employer's perspective, the analysis is all about the employer's demand and preference for college graduates. There are few 
research aimed at the cognition of the graduates to their own ability to interview, this will be our research perspective.

\section{ANALYSIS OF THE STATUS OF COLLEGE STUDENTS' INTERVIEW ABILITY}

This study explores the relationship between the gap of the college graduates' ability to interview and the cognition of college students' ability to interview from two perspectives-the employer and the university graduates. From June 12th to 25th, we took a random sample from a university which includes 405 college students. These candidates apply at six different academies such as Faculty of Science, School of Electronics and Information, School of Electrical Engineering, School of Management, School of Public Policy and Administration and School of Aeronautics and Astronautics.

The staff of a university in the recruitment of College Students' asks for six aspects, such as working potential, personality characteristics, interpersonal skills, language ability, analysis ability and appearance and behavior .Each of the six aspects assigning 25, 20, 15, 15, 15, 10 out of 100.The score of the ratio shows that the working potential is the most valued unit of the recruitment, appearance and behavior only account for $10 \%$ of the total score. This paper analyzes results of 405 college graduates in the interview. Among them, the total score of the interview reflects the overall level of college graduates' interview ability, while the score of the six indicators reflect the level of the ability of the interview.

\section{A. The overall distribution of college graduates' interview ability}

Through the analysis of the total score of 405 interviewees, the average score is 81.52 , which can be seen the ability of the university graduates to in the interview is still strong. But if from the dispersion point of view, although the standard deviation is 8.88 , it is still concentrated to some degree, the highest score is 92.62, the lowest score is 50.25, and the distribution of the results is relatively large.

In order to further explore the overall distribution of college graduates, the total score of 100 points is divided into five levels, below 60 is very poor, $60-70$ is poor, 70-80 is generally, $80-90$ is better, $90-100$ is very good. Through the frequency distribution, the university graduates' ability to interview presents a Left skewed distribution, the vast majority of students are in the lever of "a good interview skills", accounting for $64.6 \%$ of all interviewees. It is worth pointing out that the students in the upper level of the middle level accounted for $89.6 \%$ of the total, so it can be said that the level of the college students' interview ability is relatively strong and concentrated. But because the interview is the second round, so the results will have a certain error and the overall level will be a good one.

\section{B. The partial distribution of the interview ability of university graduates}

The results showed that the average score of six aspects of college students' working potential, personality, interpersonal skills, language ability, analysis ability, and appearance and behavior is followed by $20.26,16.22,12.26,12.19,8.31$, and
12.02. However, because of the different indicators of the score, the score is divided into five grades in accordance with the total score of the standard: very poor, poor, generally, better and good in turn.

Analysis the level of the ability of the interview after grouping, such as table 1.In all the abilities of the interview, the highest score gives to appearance and behavior, followed by interpersonal skills, the third is the language ability; the bottom three are the personality characteristics, analysis ability and work potential from high to low in turn. That is to say, the work potential got the lowest score which the employers value most, while appearance and behavior got higher score which the employers push to the bottom of the list.

TABLE I. THE GRADE DISTRIBUTION OF THE INTERVIEW ABILITY AFTER ClASSIFICATION

\begin{tabular}{cccc}
\hline Index & Means & $\begin{array}{c}\text { Standard } \\
\text { deviation }\end{array}$ & Variance \\
\hline $\begin{array}{c}\text { Working potential } \\
\text { Personality- } \\
\text { characteristics }\end{array}$ & 2.90 & 1.189 & 1.414 \\
Interpersonal skills & 3.56 & 0.848 & 0.719 \\
Language ability & 3.60 & 0.866 & 0.750 \\
Analytic ability & 3.54 & 0.984 & 0.968 \\
Appearance and & 3.73 & 0.574 & 1.051 \\
\hline behavior & & & 0.329 \\
\hline
\end{tabular}

\section{COGNITION AND INFLUENCE OF COLLEGE GRADUATES} ABILITY TO INTERVIEW

Because of the college graduates' understanding of the interview mainly comes from the literature on the interview skills and their own experience summary, and lack of guidance and training, so the university graduates' cognition to the ability of the interview will be biased inevitably. In order to compare with the differences of the cognition of the ability of the interview between the employer and college graduates, this study investigated the cognitive situation about the determinant of the interview and the component of the interview of college students by questionnaire.

\section{A. Cognition and influence on the decisive factors of interview.}

Based on the results of the literature and expert interviews, the paper concludes that the main factors of college graduates' interview are educational information, professional background, achievements and awards, work or internship experiences, interview performance and other factors. In the analysis, there are 53 respondents considered that the educational information and professional background are the decisive factors in the interview, accounting for $31.9 \%$; although $40 \%$ of the students think that the interview performance is the most decisive factor but It is worth mentioning that there are some graduates accounting $21.1 \%$ think that achievements and awards are the determinant, at the same time, $19.3 \%$ of the respondents regard work or internship experiences as the most important factors. The result shows that interview performance is not the most decisive factor in an interview for the graduates; they are more inclined to value educational information and professional background. 


\section{B. Cognition and its influence on the formation of interview} ability.

Although the university graduates with outstanding academic background and rich social practice experience are very beneficial to applying for job undoubtedly, but at the interview stage, what really decides the outcome of the interview is their speech and deportment, way of thinking, expression way, content of performance and the basic quality work related to when they answer the questions. To clear up this, it will help the university graduates to pay more attention to improving their comprehensive quality which refers to the professional knowledge, the award-winning experience, internship experience and some other factors when they are preparing for the interview, and furthermore that they could replace the blind social experience and ineffective self-praise as the planed and systematic self-training.

In the investigation of the university graduates' cognition to components of interview ability, university graduates are asked to select the components of interview ability from six interview ability index and sort them according to importance. Then do assignment to the selected index which chosen by the graduates the first give in 6 points, 5 points for the second assignment, and so on. Not selected indicators are given in 0 . The results of data analysis are shown in table 2 .

TABLE II. THE COGNITION OF EACH INTERVIEW ABILITIES' IMPORTANCE FOR COLLEGE GRADUATES

\begin{tabular}{|c|c|c|c|c|}
\hline & \multicolumn{4}{|c|}{ Mean Standard deviation Variance Skewness } \\
\hline Language ability & 3.78 & 1.674 & 2.801 & -.256 \\
\hline Appearance and behavior & 3.69 & 2.212 & 4.893 & -.295 \\
\hline Interpersonal skills & 3.26 & 1.765 & 3.114 & -.455 \\
\hline Personality characteristics & 3.25 & 1.871 & 3.499 & -.250 \\
\hline Working potential & 2.92 & 1.985 & 3.939 & .260 \\
\hline Analytic ability & 2.84 & 1.776 & 3.155 & .111 \\
\hline
\end{tabular}

The table 2 shows that the university graduates think that the most important in an interview is language ability, followed by the appearance and behavior, interpersonal skills and personality characteristics; the least important is the ability to work and analytic ability. Among them, the standard deviation of language ability is the least one, which reflects the opinion of university students to language ability is the most consistent. To the contrary, the opinion to the appearance and behavior and working potential has a great difference, so the standard deviation is bigger.

Because of the differences in the cognition between the graduates and employers of the importance of the college graduates' ability to interview, so misleading the orientation of self-training and efforts of university graduates from the needs of the employing units, which resulted in the low rate of college graduates' interview. To further analyze the problem, this paper investigated the way that college graduates have a better understanding of the content of the interview, details as shown in table 3 .
TABLE III. The Frequency Distribution About The Channels to KNOW the CONTENT OF INTERVIEW

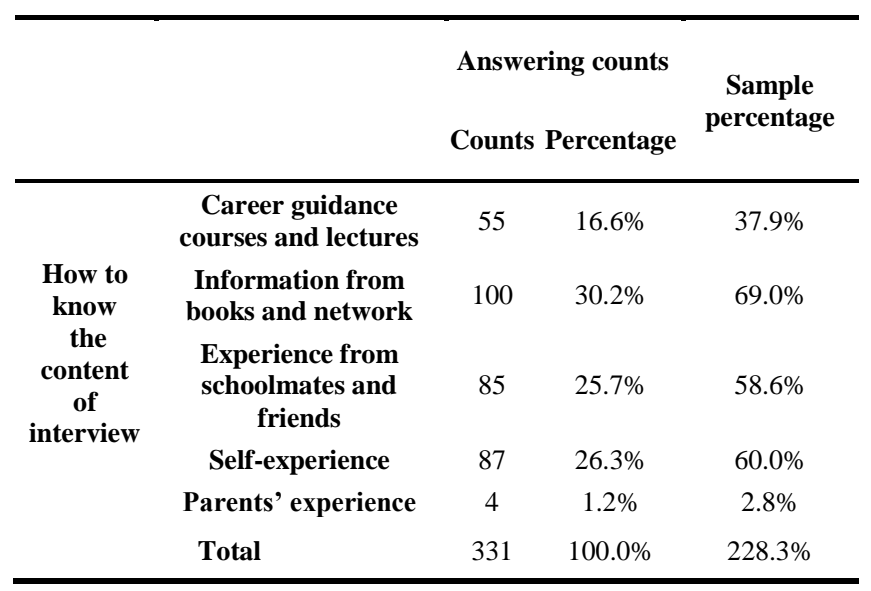

This result is consistent with the increase in the ability of the interview in the literature review. In the process of reading the literature, most of the scholars can be find out paying more attention to the importance of the instrument and language skills, and even some scholars believe that the lack of language skills is one of the important reasons for the difficult employment of college graduates. Most of the college graduates may have read these documents, and they think that these are the most important indicator of the ability to behave in a manner that is the most important. At the same time, because of the frequent and effective information sharing among the students, this error is a common view of college graduates.

\section{Self interview ability-evaluation.}

The survey about self-interview ability-evaluation of university graduates is using the Likert-type Scale, the higher score indicates that the higher the level of the ability of the interview and 5 is the best and 1 is the worst. The way of the sort is consistent with the investigation which about the level of the college students' ability in an interview. A descriptive statistical analysis of the results of College Students' selfevaluation shows that the overall evaluation of College Students' ability of self-interview is 2.36; the highest of the evaluation of the indicators is personality, followed by interpersonal skills, which is followed by the manner of appearance, language ability, analytic ability and working potential.

Variance analysis about the results of the interview and the self- evaluation of the interview ability illustrates the differences of the cognition between college graduates and the employer to the interview ability of the graduates. 
TABLE IV. THE DIFFERENCES OF THE COGNITION BETWEEN THE COLLEGE GRADUATES AND THE EMPLOYERS

\begin{tabular}{cc}
\hline Interview ability index & $\mathbf{F}$ \\
\hline Working potential & $37.675^{* * *}$ \\
personality characteristics & $74.850^{* * *}$ \\
Interpersonal skills & $87.206^{* * *}$ \\
Language ability & $91.771^{* * *}$ \\
Analytic ability & $92.745^{* * *}$ \\
Appearance and behavior & $175.688^{* * *}$ \\
\hline
\end{tabular}

By comparison, we find that college graduates and employers have different cognition to the levels of interview skills for college graduates, which shows that the university graduates have a bias in their own advantages and disadvantages, which makes the focus of college graduates in preparing for the interview may not be consistent with their own needs, so that they can't be targeted to improve the interview ability. Many students tend to think of their weak links is in the manner of instrument or language ability, so as to spend a lot of time to strengthen, but too high estimate of their own work potential or personality characteristics and more important assessment indicators, they only spent the limited energy and even give up. Eventually lead to the development of the ability of the interview is not balanced, and thus can't get satisfactory results in the interview.

\section{The Gap Between College Graduates' ABILITY tO INTERVIEW AND THE EMPLOYERS' NEED}

Due to the assessment standards are the employer interview ability requirements. That is to say, it is the each mark of the interview ability. Hence the deviations between the performance of the employees and the full marks cannot be the index for measuring the graduates' interview ability gap. Under this circumstance, we should take a relative deviation as the index, which can be derived from "each interview ability deviation /full marks". We will show it in the table 5.

TABLE V. GAP BETWEEN GRADUATES' INTERVIEW ABILITY AND EMPLOYERS' NEEDS

\begin{tabular}{ccccc}
\hline Index & employers & graduates & $\begin{array}{c}\text { Ability } \\
\text { deviation }\end{array}$ & $\begin{array}{c}\text { ability } \\
\text { deviation/Full } \\
\text { marks }\end{array}$ \\
\hline $\begin{array}{c}\text { Working } \\
\text { potential } \\
\text { personality } \\
\text { characteristics } \\
\text { Interpersonal }\end{array}$ & 25 & 20.26 & 4.75 & 0.190 \\
$\begin{array}{c}\text { skills } \\
\text { Language } \\
\text { ability }\end{array}$ & 15 & 16.22 & 3.78 & 0.189 \\
$\begin{array}{c}\text { Analytic } \\
\text { ability }\end{array}$ & 15 & 12.26 & 2.24 & 0.149 \\
$\begin{array}{c}\text { Appearance } \\
\text { and behavior }\end{array}$ & 10 & 12.19 & 2.31 & 0.154 \\
Total & 100 & 81.52 & 18.48 & 0.199 \\
\hline
\end{tabular}

Each relative deviation illustrates that the biggest difference of ability index between the college graduates and the employers is analytic ability; the deviation of the work potential and personality characteristics is slightly lower than the analytic skills. In contrast, appearance and behavior, language skills, interpersonal skills are significantly less than the other three indicators, and reduced in turn.

\section{CONCLUSION AND SUGGESTION}

The college students' interview ability is a problem which has not been studied very often, and this will be a negative effect on the opportunity for the students' employment. Because of the existence of cognitive gap, the interview ability of college graduates is generally low and uneven development, which leading to college students can't meet the needs of employers, and further highlights the difficulties of college students' employment. Therefore, we believe that the problem should be solved from the two aspects. First of all, from the perspective of college graduates, they should set up the right attitude at the beginning and pay attention to learning and developing ability in daily life, especially the personal working potential, personality characteristics and analytic skills and good behavior habits and ways of thinking. From the perspective of the guidance department for employment in university, they should provide a platform to help improving the college students' ability to interview, and continuously help students to improve their ability of interview, and lay a solid foundation for their future career.

In the long run, the university graduates want to change the disadvantage of the ability of the interview at a fundamental, they must realize the basic purpose of the interview is finding a suitable job to achieve sustainable employment. Therefore, the needs of the employers and job candidates for the job interview is the best dissidence for college graduates to prepare for the test, and the college graduates must get used to focus on the demands of the employers consistently. The author has repeatedly been a judge to participate the recruitment interview organized by different types of companies, and the author find the majority of students did not show their best performance or strong points at some aspects when they answer to the questions, so they lost the opportunity to stand out. Therefore, the college students can improve their ability from the following aspects:

First of all, be good at accumulating and summarizing the experiences and proving the working potential. Working potential is the most valued ability for the employer in the interview, which mainly includes the applicant's learning ability, organization ability, leadership, and the ability which related with the future work closely. But it is also the most difficult ability to investigate directly, and this is also the key reason why college students don't pay attention to this factor. So it is necessary for the graduates to accumulate in daily life, summarize their own typical examples, train their core skills and expertise combing with the career which they want to achieve. Meanwhile they also need to know how to convert these core skills and expertise directly to fitting the current position they apply for. If you can point out that there is a close connection between the successful experience and the future needs of the enterprise, this will be able to cause the interviewer's great interest.

Secondly, it is necessary to emphasize on the work preferences and show personality characteristics. To meet the requirements of the employer's personality characteristics, we 
must first understand what the employer wants to see is the fact that aggressive, responsible and self-confidence. Because these personality characteristics in the work often can fully mobilize their own energy, and furthermore, their work attitude will be quite positive, and the positive work state will infect others, give the workmates and the whole team's a good development finally. This trait is usually expressed in the work which people are passionate about. So when they are solving this kind of problem, college graduates can highlight the principle of choosing their own work. They could the job which is suitable for themselves, which can make their own expertise and bring a sense of satisfaction. They also can choose the position which can challenge their skill lever right now to improve themselves. According to all of these, the employers will be eager to hair you.

Thirdly, it is important to confirm the ability of deduction by yourself. From the perspective of analytic ability, it is the ability to learn and reason that the employers want to test essentially. It is a very important part in interview to think the question as solving problem as the starting point. The graduates need a clear orientation and planning for the development of their careers and they should show the ability of cognition and analysis. In the interview, the candidates should express their ideas clearly. You must state what you want to get from the work, why you can do well at the work, how you can take your advantage to the work and service for the enterprises, in this way the employers will find that you have the potential to think rationally and be quite qualified for the work

In addition, the guidance department for employment in university should do targeted guidance about the improving the interview ability of college graduates. The guidance department should set up some courses to teaching interview ability, update the information about the employers' needs in time and build a model test system about interview for the graduates, so they can have abundant resources to consummate their interview ability.

\section{REFERENCES}

[1] Yao Yuqun. "The evolution and recent development trend of College Students' employment difficulty ”. Population Journal, vol .1, pp .5,2008.(In Chinese))

[2] Liu Kuiying, Qie Lina, Huang, Chunping. "A study on the relationship between College Students' employment ability and the satisfaction of employment". Journal of Hebei university of technology, vol. 6,pp. 45 52, 2010.(In Chinese)

[3] Zhang Yingchun, Zhao Jianfeng. "Strengthen the cultivation of College Students' employment ability, improve the core competitiveness of the employment". Modern Ecnomic, vol.6,pp.2, 2009. (In Chinese)

[4] Hao Shining. "Language application strategy in the process of College Students' interview" , vol.11,pp.21-22, 2010. (In Chinese))

[5] Hollandsworth JR. "Relative contributions of verbal, articulative, and nonverbal communication to employment decisions in the job interview setting”. Personnel psychology, vol.2,pp. 359- 367, 2006.(In Chinese)

[6] Hong Xiangyang. "The seven abilities of an interview" . Software Engineer, vol.7, pp.2, 2009. (In Chinese))

[7] Song Guoxue. "Performance measurement and empirical analysis of the development of employment ability". Beijing: China Social Sciences Press, pp.135-140, 2007. (In Chinese)

[8] Einhorna LJ. "An inner view of the job interview: an investigation of successful communicative behaviors". Communication Education, vol.3,pp. 217-228,2001. (In Chinese) 